\title{
Factors Influencing Decision-Making Process In Relation To Public Service Delivery (PSD) In Malaysia
}

\author{
Rozaina Ali ${ }^{1, *}$ Ahmad Shaharudin Abdul Latiff ${ }^{1,}$ Sazali Abdul Wahab ${ }^{1}$ \\ ${ }^{1}$ Putra Business School \\ *Corresponding author.Email: rozaina.phd_mgt18@grad.putrabs.edu.my
}

\begin{abstract}
Efficient public service delivery is a main objective for every government. An important aspect of public service delivery is ensuring services provided fulfil the changing needs of the citizens and benefiting the public. However, the challenge on how best the government can serve the public continues to be the major issues in improving public service delivery. Information gap and no integrated system are affecting government's responsiveness. Despite the efficiency of service delivery system is a priority of the government, deficiency of viable, persistent, and timely information for decision-maker happens due to data silos, lack of data gathering with poor data governance and integration instead of operative unified data. The objectives of this paper are to examine and gain a better understanding of the complexities that are associated with decision-making process in relation to public service delivery from the perspective of government of Malaysia. In terms of academic contribution, this paper provides a better understanding of the critical factors for effective decision-making from the perspective of the government. With regards to practical implications, this article provides the Malaysian government and public organisations with relevant factors of consideration on how the public service delivery can be improved.
\end{abstract}

Keywords — Public Service Delivery, Decision-making, Shared Information

\section{INTRODUCTION}

Establishment of quality public services strengthens the social contract between government and citizens, which is a crucial measure of governance and strong indicator of the wellbeing of a society [1]. The public services are challenged by diverse contextual factors such as social needs, demographic shifts, lack of competencies, economic pressure, income inequality, and unequal services advancements and access [2]. An important aspect of PSD is ensuring services provided fulfil the changing needs of the citizens. Hence, efficient PSD has become a main objective for every government and is meant as the improvement of administration for better government that provides services benefiting the general public.

Significant enhancement in public sector performance can be seen among the developing country today, as government find new and innovative approach to handle public management issues. This incorporates good governance of quality PSD, accountable-decision-making, and civic commitment that requires institutions serve all stakeholders within a reasonable and acceptable period.

Governance is the process of decision-making. It implies that establishments and procedures produce results that satisfy the needs and addresses the issues of society. The disappointment of PSD in many developing nations isn't only because of the shortage of resources yet to the issues of motivation, responsibility and governance that contrast from one aspect to another [3, 4]. Consequently, such shortcomings ultimately result in the dissatisfaction of people for not receiving appropriate services by the public agencies.
Considering that the services given to the public are not only provided by a single governmental agency but also involve inter and intra governmental agencies which may have complex structure and involve many stakeholders that can cause lack of coordination and conflict of interests [5, 6]; it is important for PSD to be solid and reliable in order to gain the trust of the public and meet their expectations. Hence, there is a need to do a change in communication where government is to play a more dynamic role in problem-solving, together with making decisions in creative ways that may lead to positive change.

The main challenge is for the government to get a set of competencies to support the interoperability, needed for integration as well as the appropriate understanding of information to make decisions. At the point when government agencies and departments work in silos, they cannot engage in the kind of collaboration that is critical to deliver on the government's obligations. Like many other countries, the Malaysian public is increasingly demanding government efficiency and quality services, and the government knows that transformation must happen.

The urgency of transformation is intensified by factors such as increasing urbanisation, an ageing population and the need to reskill a large portion of the workforce to adapt to innovations in technology [7]. The administration of Malaysian public sector organisation has experienced considerable changes intended at conveying improved services in the efficiency and effectiveness due to the rise of global economy and technology, and also increased societal needs $[8,9]$. 
Subsequently, continuous effort has been carried out by the Malaysian government to improve its PSD. For instance, the use of ICT in public sector aims to refining information and service delivery, inspiring citizen involvement in the decision-making process and making government more accountable, transparent and effective [10]. Based on the Strategic IT Plan (2016-2020) by Malaysian Administrative Modernisation and Management Planning Unit (MAMPU), the Malaysian Government had emphasised on the importance to have an inclusive digital government that could spearhead the citizen-centric service delivery [11]. The plan is a continuity from series of ICT plans that has presented the economic transformation plan to accommodate quality economic execution through initiatives like zero faceto-face service delivery; paper less government; encouraging information sharing; cross-agency coordination; government shared services; and upskilling internalisation of public sector ICT personnel.

This paper highlights the importance of decision-making and pertaining issues with regards to decision-making to better improve PSD. It provides more contextual information to decision-makers, helping them to understand the complexity of decision-making process across government agencies. In terms of academic contribution, this paper provides a better understanding of the critical factors for effective decision-making from the perspective of the government. With regards to practical implications, this article provides the Malaysian government and public organisations with relevant factors of consideration on how the public service delivery can be improved.

The rest of this paper is organised as follows. Section 2 provides a review of the literature related to the prominent issues of decision-making. Section 3 describes the conceptual framework of research towards improving service delivery before concluding the paper in section 4 .

\section{THE IMPORTANCE OF DECISION-MAKING IN PUBLIC SERVICE}

The needs to improve public administration would be to improve the effectiveness and efficiency of the government's decision-making process to ensure the public gets the quality service needed. We are now in an era in which we must accommodate and adapt to the changing needs of the citizens, and these needs come in waves fuelled by a more educated and technologically savvy population. The approaches that government used to undertake have changed from providing counter services to kiosks that have no limited time and can function effectively.

There is a massive scope of advances that governments can saddle to improve execution and its SD such as digital interfaces for citizens, automation of routine tasks (for example, processing of forms), advanced analytics (with or without big data), and artificial intelligence [12]. Client support has progressively become a focus for public sector to improve its delivery services. A customer-driven services, one that intents to provide the most ideal client experience utilising the most efficient delivery model, should characterize their leading service delivery.
Thus, decision-making plays an important role in PSD efficiency by adopting customised approach for government to execute their initiatives effectively. In the present condition with increased elements and interdependencies, government looks for better approaches to steer the procedure to shield public values and venture results which mirror the actual delivery of public service. However, much of any government's knowledge exists in the form of unstructured resources such as project summary reports, research, and development reports, etc. making it hard to find and interpret them for decision-making. Thus, for PSD to be solid, it needs fast and timely decision-making to gain the trust of the public and meet their expectation. To strengthen the governance of the digitalisation of PSD, particularly in the context of government of Malaysia, several approaches are to be in place such as creating a centralised strategic government digital service structure, strengthening existing systems and data governance structure, utilising Public Sector ICT Strategic Plan to continuously consolidate the management of service delivery standard and to standardise service delivery performance in the Public Sector [13].

\section{ISSUES ON DECISION-MAKING}

Abstractly, public service of any country is a foundation of governance and administration made essentially to furnish open with great necessities (water, electricity, healthcare, quality education and transportation frameworks among others) to the citizen in the most productive and successful strategy [1]. These days, the PSD is implied as the improvement of organisation for better government that gives services profiting the overall community. Thus, government needs to make decisions in a creative way that may lead to positive change to satisfy the community. However, there are several issues on decision-making that hinder the government to act efficiently.

\section{A. Information Gap for Effective Decision-Making}

Information gap is one of the identified issues in decision-making that contributed to the cause of less responsiveness in PSD [8, 16]. In many cases decision makers use instinct to make decision. However, for most complex and important decisions at the organisational level it gets imperative to appropriately structure the issue and ensure the options are explicitly assessed in terms of the criteria. Organisation makes decisions daily [17]. Recording such decisions is vital to allow other members in the organisation to benefit from past experiences, and to assist new workers in adapting into the organisation.

Ultimately, government cannot make fast decision because lack of effective, constant, timely, and quality data for decision makers as a result of data silos, pour data collection, integration and information governance rather than effective unified data [18]. decision-making is a key action for management in any organisation. The procedure of decision-making includes settling on a decision from a lot of options. Today, many high-level procedures identified for decision-making are manually made. This is because the available information is frequently in the form of reports and pre-set data [19]. 
Decision makers often inspect goals, values and criteria in assessing this set of choices. There are normally numerous, often conflicting, criteria that should have been accessed in decision-making. One way to do this is to recognise all the business processes that will be affected by each option and afterward to inspect these business processes in detail to decide the full extent (for example outcomes) of the impact on the business procedure [20-22]. To do this effectively requires analysing the captured data in a structure manner and interlinked across agencies as knowledge for decision-making.

A decision-making process needs access to domain knowledge to the outcomes of applying an alternative decision where the knowledge is often characterised as a set of basic definitions such as alternatives, conditions, decision matrix, and decision itself. Information that is relevant for decision-making is assembled and used as an input in a decision-making process. Dixon (2010) explained on knowledge and truth in relation to human nature where human will make selections that they expect will benefits them, if they have complete and certain knowledge of, and the capability to compute the outcomes of the chosen alternative and varied courses of action. Thus, in decisionmaking, the honesty of a knowledge claim should be determined only by adopting objective truth criteria, which means that for a knowledge claim to be true, it must be with fact [23].

Nonetheless, government information is mostly offered in heterogeneous formats, missing clear semantics that explain what the information portrays. The information collected likewise showed in manners that is not clearly reasonable to a broad range user network that need to make informed decisions. Evidently, it is a challenging task for analysts to totally evoke all requirements shared by the organisation's decision makers. With a large number of information accessible from external sources such as social media and web data, choosing the right arrangement of data and reasonable methods for an analysis itself is troublesome and time-consuming [24].

To enforce the information sharing in the public administration, there is a need to establish integrated applications that can produce insights in a suitable pace out of a countless information in different formats. This coincide with Engin and Treleaven (2019) research on "Automating Public Services and Supporting Civil Servants in using Data Science Technologies"; where government data landscape is characterised by a multiple sources such as official records and census or statistics that are applicable in governments' operations and gives countless benefits for economic development, political, scientific and social innovations [18]. As such, there is a growing need to study the extent to governments operation that demands more in the responsibilities in data-work, particularly in terms of ethical data collection, methodological transparency, and curation. Therefore, consolidation of data from several sources for more efficiency and effectiveness in decision-making contributes to governments' business process redesign and operations that lead to cost decrease, information, and service retrieval enhancement.
This includes information and services availability (anytime, anywhere), customer orientation and better security [25]. Consolidated information also not only can feed decision-making but planning and policy making that can moreover serve as a follow-up tool, improving the implementation processes and the functioning of implementor organisations [26].

\section{B. Inadequate Coordination of Information Across Public Agencies}

Services given to public not only provided by one governmental agency but also involve inter and intra governmental agencies as well and involve many stakeholders. These services are frequently involving several layers (repetitive) and must adhere to some procedure. This can occasionally lead to irregularity in practice and possible human judgment mistakes. The government cannot deliver their service effectively because there is no integrated services among government agencies [10, 16, 27-29]. Most services are not linked within and across ministries and agencies; mainly due to the segregation way of functioning, incompatible systems or technologies rendered in agencies. When government agencies and departments work in segregation, they cannot engage in the kind of collaboration that is critical to deliver on the government's obligations. This resulting in lack of coordination among government agencies in providing seamless service delivery and conflict of interests among stakeholders $[6,30,31]$.

So, it is important to have mutual understanding of standard operating procedure (SOP) within the government agencies to improve dependability and quality of the services [32]. Since involvement by many stakeholders occur in PSD, there is a need to do an adjustment in expectations for interactions and reduce bureaucracy [31]. The bureaucracy refers to the level of government that is responsible in the delivery process. The level can be federal or state level or depend on the systems being practiced either centralised or decentralised [31]. The level of government is important since it depicts the public accessibility of services provided. Adding on to this, feedback received from the public also needs to be carefully analysed and the information captured is to be shared among government agencies to identify flaws in the approach undertaken by the government [18]. Merging customer satisfaction information with daily operational data such as the call-centre report and number of face-to-face visits, will reveal extra insight rather than referring to surveys and feedback forms [14].

However, a report from World Bank (2019) quoted that Malaysia is not an open economy in the sense that data sharing is a significant issue and the government doesn't share so much information, even within its own departments or with the public. The report also stated that citizens' feedbacks were not taken into consideration by the government in designing their programmes [33]. Hence, to link the gap between customers' expectations of service delivery, governments need to constantly improve their customer service skills and emphasis on the ability to benefit citizens to resolve their queries and problems quickly. 
As various organisations work in remoteness of one another, frequently the information that is gathered is stored in proprietary formats that are strictly combined with certain software and equipment used to gather, store and process. This implies the stored data is of limited use to other group except if they have that equivalent programming or software, causing the capacity and advantages for information re-use is either low or even non-existent [34]. This can be particularly problematic and costly for governments as information that might be gathered from that data to better assist in making decisions is beyond the capacity and for them to compile the similar information can be very expensive.

\section{Lack of Data Driven Initiative to Utilise Big Data for PSD Efficiency}

Big data promises to change public decision-making for the better by making it progressively receptive to real demand and policy effects. For instance, incorporating SM data to help the organisations with the decision-making process in connection to the organisational goals [22]. Nonetheless, a great part of the PSD research didn't get a lot of consideration on consolidating the BD. Recent work on Big data in public decision-making expect a rational perspective on decision-making, which has been greatly criticised in the public administration debate [35].

Even though the Malaysian government is of the view that the key enablers to ensure success strategies for an effective government delivery system is the use of data analytics [36], the main challenge is for the government to get a set of competencies to support the interoperability needed for integration, as well as the appropriate understanding of information to make decisions. Indeed, even data management policies and procedures to support public policy design and execution exist, the degree of interconnectedness and coordination of government data is still low [4]. Government agencies know about the information they hold, with quite a bit of this information is computerised, yet no comprehensive inventories within or across agencies in dealing with that information. Furthermore, digitisation of public services is progressing slowly [37].

An indicator from World Bank Report released on $1^{\text {st }}$ July 2019 showed that Malaysia performed not very well in digitisation and technological advances, which the government had not had the option to coordinate into its framework to provide services. The report additionally expressed, access to data was challenging and remains an area of concern for potential and genuine data-users and other stakeholders [33]. The need for more operative and extensive shared communication between governments and citizen isn't only a product of technological progress. Information irregularity among citizens and public officials may affect public officials to be less sensitive to citizens' demands and needs too which influencing public service's responsiveness [28]. To revolutionise and provide digital access to public service given to citizens, the utilisation of technology focuses on the automation of government internal process is required to improve PSD [38].
A continually developing amount of data (from internal and external data) represents source of knowledge to which organisation can implement data-driven decisions. Capitalising on external data such as social media data and web data are part of big data that can be used to increase government's service delivery [39]. Given the clear link between digital technology and national prosperity, it is necessary for the government to ensure to takes advantage of the emerging digital technological landscapes to expand the range of its service delivery. With this, governments are moving towards data-driven decision-making which contributes to better improvement in PSD.

\section{DISCUSSION AND CONCLUSION}

Delivering public services in a timely and citizenfriendly manner will ultimately improves the administration in the government department and agencies. Based on Appendix 1, there were three key issues have been identified to be the cause of less efficiency of government in delivering good services. Ultimately, integrated services and shared information across government agencies found to be the possible solutions that can enhance government's service delivery.

Efficient PSD is the attention of every government worldwide. The needs to improve in public management is to ensure the productivity and efficiency in order to provide the citizens with the good services they need. Living in the era in which government must accommodate and adapt to the changing needs of the citizens demanded effective and efficient decision-making process that can assist the decision makers. This in turns requesting the government to be more responsive in providing services to the public by eliminating bureaucracy within different level of government. Even though conventionally decision-making is regularly based on rules of thumb rather than systematic analysis, the shift of public sector organisations towards a digital-era governance plays a wide-ranging series of transformation on how public services are planned and delivered to citizens. The effects of knowledge production and use have significant economic impact beyond management of capital and labour, and therefore require serious managerial attention (within organizations) and policy attention (within governments) at senior levels [40].

This paper seeks to establish factors influencing decision-making for PSD by identifying the critical information that are relevant to increase government's responsiveness. Information like historical data, current data, feedback data and dynamic data are among structured data that are relevant to be analysed and stored for decisionmaking process [41]. Information gathered from outside sources that are relevant to the organisation will allow precise combination of datasets for better decision-making where it permits decision makers to harvest interconnected information for analytics [42, 43]. 


\section{REFERENCES}

[1] Akintunde O. Governance and Public Service Delivery in Nigeria: The Role of Information and Communication technologies CUCEN2017.

[2] Lopes NV, Dhaou S Ben. Public Service Delivery Framework. 2018; 101-110.

[3] Lopes NV, Soares DS, Nielsen MM, et al. Research Gaps on Public Service Delivery. 2017; 465-474.

[4] World Bank Group. Malaysia Economic Monitor: Re-energizing the Public Service. 2019; 76.

[5] Shaharudin A, Latiff A, Haron H, et al. Software Engineering Approach for Domain Ontology Development: a Case Study of Islamic Banking Product. 2017; 3: 36-53.

[6] Khan GF. Social Media for Government. Soc Media Gov 2017; 7-21.

[7] Nor MHM (The E. MySay: Achieving successful and sustainable public sector reform.

[8] Husin R, Saad R, Othman Z. E-kerajaan: tinjauan dan perlaksanaanya di Malaysia. J Technol Oper Manag 2017; 12: 7-14.

[9] Siddiquee NA, Xavier JA, Mohamed MZ, et al. What Works and Why? Lessons from Public Management Reform in Malaysia What Works and Why? Lessons from Public Management Reform in Malaysia. Int J Public Adm 2017; 00: 1-14.

[10] Dzikrullah F, Rinjani MA, Angga M. A framework design to develop integrated data system for smart e-government based on big data technology. Bull Soc Informatics Theory Appl 2017; 1: 41-51.

[11] MAMPU. The Malaysian Public Sector ICT Strategic Plan.

[12] Allas T (The MC for G, Checinski M (The MC for G, Dillon R (The MC for G, et al. How to Triple The Success Rate of Delivering.

[13] MAMPU. Public Sector CIO CONVEX 2017. 2017.

[14] Dudley E, Lin D-Y, Mancini M, et al. Implementing a citizen-centric approach to delivering government services. McKinsey Insights 2015; 3-9.

[15] Makareviciute BR. How digital can bring better government.

[16] Japheth L, Ngigi M, Sang A. Citizens ' Perceptions On The Status Of Governance ( Public Service Delivery ) In The Counties: The Case Of Migori County , Kenya. 2016; 21: 29-32.

[17] Guizzardi R, Susi A. Aligning Goal and Decision Modeling. 2018; 2: 124-132.

[18] Engin Z, Treleaven P. Algorithmic Government: Automating Public Services and Supporting Civil Servants in using Data Science Technologies. Comput J 2019; 62: 448-460.

[19] Dalmau-Espert JL, Llorens-Largo F, CompanRosique $\mathrm{P}$, et al. Leveraging information for high level-of-Abstraction organizational processes. Int $J$ Des Nat Ecodynamics 2016; 11: 416-427.
[20] T.Izhar TA, Torabi T, Bhatti MI. Using Ontology to Incorporate Social Media Data and Organizational Data for Efficient Decision - Making.

[21] Chierici R, Mazzucchelli A, Garcia-Perez A, et al. Transforming big data into knowledge: the role of knowledge management practice. Manag Decis. Epub ahead of print 2018. DOI: 10.1108/MD-072018-0834.

[22] T.Izhar TA, M.Shoid MS, M.Jawi AI, et al. Retrieving Information from Social Media using Ontology. Int J Acad Res Bus Soc Sci 2017; 6: 1-18.

[23] Dixon J. Symposium The Dismal (Delusional and Dangerous) "Science" of Economics and the "Capture" of Public Administration: Naive Neoclassical Economics and the Promised Land of Privatization. Adm Theory Prax 2010; 32: 348-372.

[24] Bandar M, Behnaz A, Rabhi FA, et al. From Requirements to Data Analytics Process: An Ontology-Based Approach. 2019; 1: 543-552.

[25] Lopes NV, Dhaou S Ben. Public service delivery framework: Case of Canada, China and Estonia. ACM Int Conf Proceeding Ser 2018; 101-110.

[26] OECD. Draft Policy Framework on Sound Public Governance, http://www.oecd.org/gov/draftpolicy-framework-on-sound-public-governance.pdf (2017).

[27] Anthopoulos L, Reddick CG, Giannakidou I, et al. Why e-government projects fail? An analysis of the Healthcare.gov website. Gov Inf $Q$ 2016; 33: 161173.

[28] Eom SJ, Hwang H, Kim JH. Can social media increase government responsiveness? A case study of Seoul, Korea. Gov Inf Q 2018; 35: 109-122.

[29] Giest S. Big data for policymaking: fad or fasttrack? Policy Sci 2017; 50: 503-518.

[30] Kuitert L, Volker L. Public Service Delivery in Hybrid Organisations public management reform and horizontalisation as main challenges for public leaders.

[31] Ahmad Z. Public Service Delivery: Do We Need any Reforms? In: Ladiqi S, Wekke IS, Seftyono C (eds). Department of Politics and Civics Education, Universitas Negeri Semarang., 2017.

[32] Buranarach M, Ruangrajitpakorn T, Supnithi T, et al. An ontology-based approach to supporting knowledge management in government agencies: A case study of the Thai excise department. IEICE Trans Inf Syst 2018; E101D: 884-891.

[33] Leoi SL (The SO, Chung C (The SO. World Bank : Efficiency of Malaysia' $\mathrm{s}$ civil service has stagnated. 2019.

[34] Roy J. Digital government and service delivery: An examination of performance and prospects. Can Public Adm 2017; 60: 538-561.

[35] van der Voort HG, Klievink AJ, Arnaboldi M, et al. Rationality and politics of algorithms. Will the promise of big data survive the dynamics of public decision making? Gov Inf $Q$ 2019; 36: 27-38. 
[36] Bernama. Govt agencies urged to use technological advances to boost service delivery.

[37] Giest S, Raaphorst N. Unraveling the hindering factors of digital public service delivery at streetlevel: the case of electronic health records. Policy Des Pract 2018; 1: 141-154.

[38] Nielsen MM. Tackling identity management , service delivery, and social security challenges: technology trends and partnership models. 2019; $1-$ 5.

[39] Young SD. Behavioral insights on big data : using social media for predicting biomedical outcomes. Trends Microbiol 2014; 22: 601-602.

[40] Lambe P. The unacknowledged parentage of knowledge management. J Knowl Manag 2011; 15:
175-197.

[41] Sathick J, Venkat J. A generic framework for extraction of knowledge from social web sources (social networking websites) for an online recommendation system. Int Rev Res Open Distance Learn 2015; 16: 247-271.

[42] Izhar TAT, Torabi T, Ishaq Bhatti M. Using ontology to incorporate social media data and organizational data for efficient decision-making. Int J Comput Inf Syst Ind Manag Appl 2017; 9: 922.

[43] Fayzrakhmanov RR, Sallinger E, Spencer B, et al. Browserless Web Data Extraction : Challenges and Opportunities. 2018; 1095-1104.

\section{IMPROVEMENT IN PUBLIC SERVICE DELIVERY EFFICIENCY}

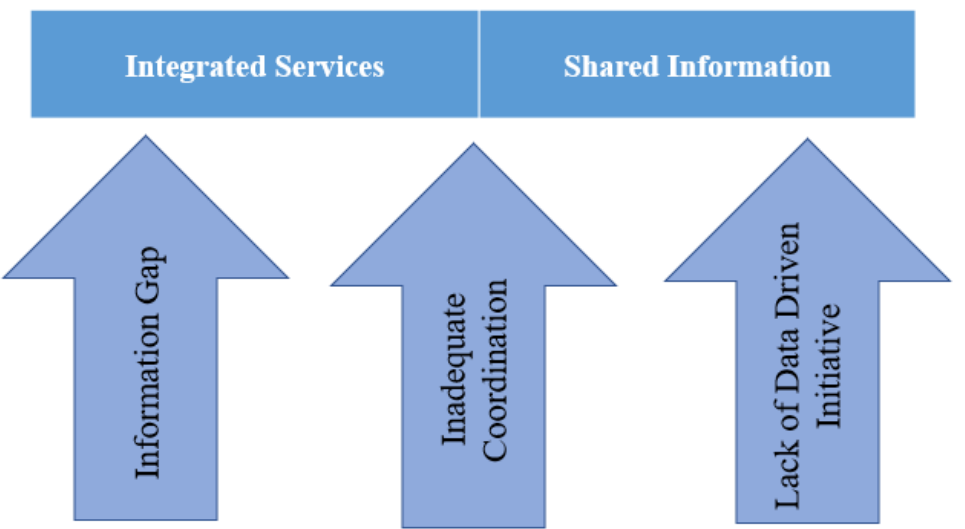

Issues on Decision-Making in Public Service Delivery 